\title{
DOES THE NUMBER OF PHARMACIES A PATIENT FREQUENTS AFFECT ADHERENCE TO STATINS?
}

By Russell Christie ${ }^{1}$, Ingrid Sketris ${ }^{1,2}$, Pantalis Andreou ${ }^{1}$, Anne Holbrook ${ }^{3}$, Adrian R. Levy ${ }^{1}$

Acknowledgement: Dr. Hala Tamim ${ }^{4}$

${ }^{1}$ Department of Community Health and Epidemiology, Dalhousie University, Halifax, NS.

${ }^{2}$ College of Pharmacy, Dalhousie University, Halifax, NS.

${ }^{3}$ Division of Clinical Pharmacology \& Toxicology, Department of Medicine, McMaster University, Hamilton, ON.

${ }^{4}$ Faculty of Health, York University, Toronto, ON.

Corresponding Author: adrian.levy@dal.ca

Submitted: November 11, 2016. Accepted: April 10, 2017. Published: May 302017.

\begin{abstract}
\section{Background}

We hypothesized that medication adherence is affected by the number of pharmacies a patient frequents.
\end{abstract}

\section{Objective}

The objective was to estimate the strength of association between the number of pharmacies a patient frequents and adherence to statins.

\section{Methods}

Using administrative data from the Nova Scotia Seniors' Pharmacare program, a retrospective cohort study was conducted among subjects aged 65 years and older first dispensed a statin between 1998 and 2008. The Usual Provider of Care (UPC), was defined as the number of dispensation days from the most frequented pharmacy divided by the total number of dispensation days. Adherence was defined as a Medication Possession Ratio of $80 \%$ or greater. Data were analyzed using hierarchical linear regression.

\section{Results}

The cohort of 25,641 subjects was 59\% female with a mean age of 74 years. During follow-up, subjects filled prescriptions in a median of $2($ mean $=2$; standard deviation $=0.88)$ pharmacies and visited pharmacies a median of $28($ mean $=30)$ times. During that time, $61 \%$ of patients used one pharmacy exclusively. Among subjects using 1 pharmacy, 59\% were adherent while 58\% using more than one pharmacy were adherent. However, upon adjustment for differences in distributions of age, sex, and other confounders, subjects who used more than one pharmacy had $10 \%$ decreased odds of statin adherence (odds ratio: 0.90, 95\% confidence interval: $0.86-0.96)$. These results were robust in sensitivity analyses.

\section{Conclusions}

Among seniors newly starting statin therapy, using a single community pharmacy was modestly associated with adherence.

Keywords: medication adherence, community pharmacy, continuity of care

\section{BACKGROUND}

The problem of medication non-adherence is so large that the World Health Organization (WHO) concluded that increasing medication adherence would be more beneficial for population health than developing new treatments. ${ }^{1}$ This view was based on multiple reports that show approximately $50 \%$ of persons prescribed long-term medication are adherent 1 year after initiating treatment. ${ }^{1}$ Many interventions have attempted to improve medication adherence with limited success; many other studies seek to identify 
the factors that promote or inhibit adherence, hoping to identify targets for future interventions. ${ }^{1-4}$

We hypothesized that medication adherence is affected by the number of pharmacies a patient frequents; defined as the extent to which a single pharmacy dispenses all medications to the patient. This definition is adapted from the definition of continuity of physician care. ${ }^{5}$

Use of a single pharmacy could influence medication adherence by modifying patient beliefs about adherence and fostering a strong provider-patient relationship, which then translates to increased information uptake and utilization, and subsequently improved adherence, while also reducing the risk for medication-related problems. ${ }^{6-8}$ However, a literature review of Medline, 1960 to August 2015, identified only one study that directly assessed this association. ${ }^{9}$ Five additional studies identified patient characteristics associated with the use of a single pharmacy. ${ }^{8,10-13}$ There are currently no studies that show that the use of a single pharmacy influences clinical outcomes.

Statins were chose to study the association between adherence and pharmacy attendance because they are frequently prescribed and non-adherence has been linked to many negative health and economic outcomes. ${ }^{14,15}$

The objective was to estimate the strength of association between number of pharmacies a patient frequents and adherence to statins.

\section{METHODS}

\section{Study Design}

This was a retrospective cohort study of subjects enrolled in the Nova Scotia Seniors' Pharmacare Program (NSSPP). Ethics review was obtained from the Dalhousie University Health Sciences Research Ethics Board in May, 2013 (Reference number: 2013-2971).

\section{Data Sources}

Data were obtained from Health Data Nova Scotia (HDNS) at Dalhousie University. ${ }^{16}$ HDNS housed anonymously coded records from the NSSPP database, the Canadian Institute for Health Information Discharge Abstract Database (CIHI-DAD), and the Medical Services Insurance (MSI) database. The NSSPP database contained patient level information as well as information on medications claimed for coverage.
Enrollees in the NSSPP were seniors aged 65 years and older, who were residents of Nova Scotia with a valid Nova Scotia health card. ${ }^{17}$ Seniors could not register in the program if they had any other public or private health insurance that covered most prescriptions. ${ }^{18}$ The plan required enrolled seniors to pay a yearly premium as well as a co-payment for their prescriptions. At the beginning of this study, in the 1998-1999 fiscal year, 88\% of seniors in the province were enrolled in the program. ${ }^{19}$ Ten years later, in the $2007-2008$ year $70 \%$ of eligible seniors in NS were enrolled in the program, receiving a total of $3,255,724$ prescriptions. ${ }^{20}$ Of residents enrolled in the program in the 2007-2008 year, 99\% claimed a medication for reimbursement. ${ }^{20}$ The program did not cover medications provided in hospital, outpatient clinics or corrections facilities. As with other Canadian public medication reimbursement program databases, the quality of the data contained in the NSSPP is thought to be high. ${ }^{21-23}$ The CIHI-DAD contained a discharge summary of the demographic, administrative and clinical information from all hospital separations from acute care, same day surgery, rehabilitation or psychiatric facilities in Nova Scotia. The MSI database contained dates and records of insured physician services that were paid for by the Nova Scotia provincial health system.

\section{Study Population}

Subjects were included in this study if they were a member of the NSSPP at any time between January 1, 1996 and April 30, 2008 and had received a first (index) prescription for a statin medication after January $1^{\text {st }} 1998$ and at least one year after enrolment in the program. Patients were identified in the NSSPP by WHO ATC codes C10AA01- C10AA05 and C10AA07. ${ }^{24}$ These codes correspond to the statins available in Canada. Subjects were excluded if they had; a statin prescription in the 2 years prior to January 1, 1998; not been enrolled on the NSSPP for at least one year prior to the first statin prescription; a WHO ATC code for cerivastatin (C10AA06), a diagnosis or procedure for dialysis or kidney transplant; or a prescription for a non-statin cholesterol lowering medication within the 365 days prior to the first statin prescription. Subjects were also excluded if they had only one dispensation date for any medication, 
hereafter referred to as a pharmacy visit, prior to the first (index) statin.

\section{Exposure}

We determined single pharmacy use by calculating the UPC index. ${ }^{5}$ The UPC was calculated as the number of dispensation days from the most used pharmacy divided by the total number of pharmacy dispensation days. The UPC was assessed at least one year but not more than 2 years prior to the first statin dispensation (Figure 1). All dispensations successfully submitted to the NSSPP that occurred during that time, regardless of medication class, were used to calculate the UPC. This period was chosen because, in Nova Scotia, medications are commonly filled at 30 to 90 day intervals, resulting in a minimum of 4 prescriptions fills for chronic medications each year. Shorter pre-statin periods could inflate the values of continuity for those subjects. ${ }^{25}$ Subjects who redeemed multiple medications on the same fill date were considered to have received one dispensation on that date in order to accurately reflect the number of visits to each pharmacy.

The UPC was analyzed as a dichotomous variable; a score of 1.0 indicated that the subject had only used a single pharmacy, and scores less than 1.0 indicated that more than one pharmacy was used. The UPC has been referred to as "pharmacy loyalty" or the "fidelity coefficient" in previous studies. ${ }^{10,13}$

\section{Outcome}

Adherence was approximated by the Medication Possession Ratio (MPR), which is the ratio of the number of days of medication supplied during the adherence assessment period to the number of days in the adherence assessment period. ${ }^{26}$ In this study, the MPR was calculated for the 365 days immediately following the first statin prescription (see Figure 1). Subjects were considered to be adherent if their MPR was $\geq 0.80$, which is the usual cut-point for signifying adherence to cardiovascular medications. ${ }^{21,27,28}$ The MPR was calculated for the statin medication class, not for individual statins within the class.

\section{Covariates}

Ten potential confounders that may have influenced the exposure-outcome relationship were determined $a$ priori, based on the current literature, biological/social plausibility and the ability to calculate them. ${ }^{2,5,29-38}$ Covariates were collected at the time of the first statin prescription, and were gathered from the preceding one year. Demographic variables included: subject age, sex, hypertension diagnosis, average 2001 household income by census enumeration area, and urban or rural place of residence. A binary variable indicated the use of greater than 4 distinct prescribed medications dispensed at the WHO ATC code level, hospitalization in the year prior to index, and having greater than 4 physician visits in the year prior to index. Statin dose (low or high) was determined using the definition published by Law and colleagues in the British Medical Journal. ${ }^{39}$ The number of unique physicians who prescribed a statin was measured during the 365 days after the first statin dispensation.

\section{Analysis}

Statistical analysis was completed using SAS version 9.3 (SAS Institute Inc., Cary, NC, USA). The statistical significance for all tests was set to $\alpha=0.05$. The unit of analysis was the person to whom the statin was dispensed. Hierarchical linear regression, clustered by index pharmacy was used to estimate the strength of

FIG 1. Study timeline.

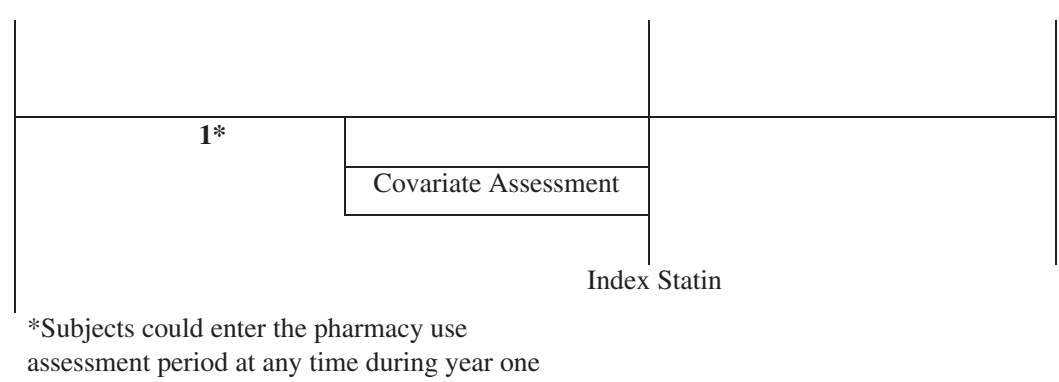

J Popul Ther Clin Pharmacol Vol 24(2):e50-e60; May 30, 2017

(c) 2017 Journal of Population Therapeutics and Clinical Pharmacology. All rights reserved. 
association between the UPC index and adherence to statins, measured by the MPR. Clustering was used to take into account the variability at both the pharmacy and subject levels, while allowing the pharmacy effect to be analyzed. ${ }^{40,41}$ A binomial distribution of the MPR was used in the model. In addition to the UPC, the final model was designed to contain the 10 selected patient level covariates. Sensitivity analyses were conducted by changing the adherence level to a MPR of 0.75 and 0.90 , restricting the study population to subjects living in urban areas or to subjects who had been hospitalized in the year prior to their index statin because these populations may have had altered adherence and/or continuity behaviour. Additional sensitivity analysis, restricting the study population to subjects who had filled thirteen or fewer statin prescriptions during the adherence assessment period was also conducted.

\section{RESULTS}

A total of 31,592 subjects with a first statin prescription between January 1, 1998 and April 30, 2008 met inclusion criteria. These subjects were dispensed a total of 1,532,464 prescriptions in the 2 years prior to their index statin, a mean of 48.5 per person. After exclusions (details in Figure 2), 25,641 (81.2\%) of the original subjects remained in the dataset.

Demographic characteristics of the study population are found in Table 1. The cohort comprised of
25,641 subjects, was $59 \%$ female had a mean age of 74 years. Subjects filled prescriptions in a median 2 $($ mean $=2 ;$ standard deviation $=0.88)$ pharmacies, visited pharmacies a median of $28($ mean $=30)$ times and received a median of 44 (mean $=51.6$; standard deviation $=47.8$ ) dispensations. Median annual household income was $\$ 44,800$ (mean $=\$ 46,500$; standard deviation $=\$ 16,000$ ). Most subjects received a low-dose statin as their index prescription. During the adherence assessment period, subjects were dispensed a statin a median of 5 (mean $=6.0$; standard deviation $=3.8$ ) times.

Pharmacy use was skewed toward 1.0, with $60.9 \%$ of subjects having a UPC equal to 1.0 , indicating exclusive use of one pharmacy. The mean UPC was 0.92 (standard deviation: 0.15). The median UPC was 0.89 and the interquartile range was 0.50 . Among the $39.1 \%$ of patients with a UPC less than 1.0 , the mean UPC was 0.79 (standard deviation: 0.17 ). The mean MPR for the study population was 0.73 (standard deviation: 0.31 ), and was skewed toward 1.0 with $58.9 \%$ of subjects having an MPR greater than or equal to 0.80 . The median UPC was 1.0 and the interquartile range was 0.10 . Adherence was observed in $59 \%$ of subjects who used a single pharmacy and in 58\% who used more than one pharmacy.

Table 2 shows the patient characteristics associated with single pharmacy use. Female sex was associated with lower odds of single pharmacy use, while those

FIG 2. Summary of subject selection.

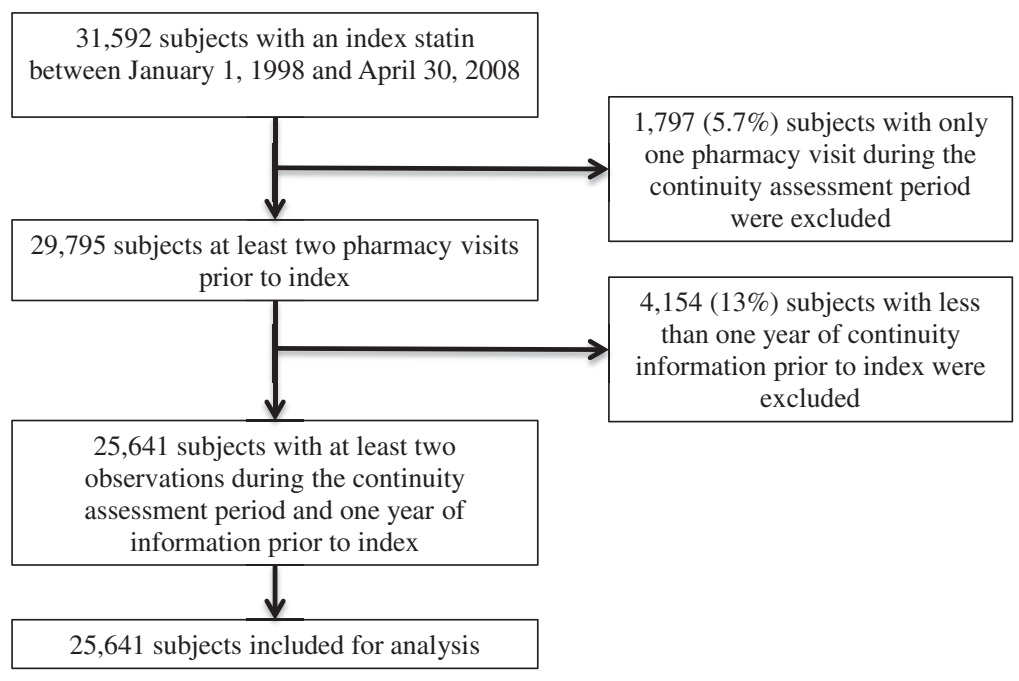

J Popul Ther Clin Pharmacol Vol 24(2):e50-e60; May 30, 2017

(C) 2017 Journal of Population Therapeutics and Clinical Pharmacology. All rights reserved. 
TABLE 1A Demographic and clinical characteristics of subjects who met inclusion criteria ${ }^{\text {a }}$ (Categorical Variables)

\begin{tabular}{|c|c|c|}
\hline \multicolumn{2}{|c|}{$(N)=25,641$} & \multirow{2}{*}{\begin{tabular}{|l|}
$\%(N)$ \\
$41.4(10,614)$
\end{tabular}} \\
\hline Sex & Male & \\
\hline & Female & $58.6(15,027)$ \\
\hline \multirow[t]{4}{*}{ Age, years } & $65-69$ & $29.6(7,600)$ \\
\hline & $70-74$ & $29.5(7,555)$ \\
\hline & $75-79$ & $21.8(5.576)$ \\
\hline & $\geq 80$ & $19.2(4,910)$ \\
\hline \multirow[t]{4}{*}{ Income tertile $^{\mathrm{b}}$} & High & $32.1(8,246)$ \\
\hline & Moderate & $32.1(8,249)$ \\
\hline & Low & $32.1(8,236)$ \\
\hline & Unknown & $03.6(910)$ \\
\hline \multirow[t]{3}{*}{ Place of residence } & Urban & $58.6(15,024)$ \\
\hline & Rural & $41.4(10,611)$ \\
\hline & Unknown & $0.02(6)$ \\
\hline \multirow[t]{2}{*}{ Use of greater than four medications ${ }^{c}$} & Yes & $79.6(20,401)$ \\
\hline & No & $20.4(5,240)$ \\
\hline \multirow[t]{2}{*}{ Hospitalized $^{\mathrm{c}}$} & Yes & $38.0(9,756)$ \\
\hline & No & $62.0(15,885)$ \\
\hline \multirow[t]{2}{*}{ Greater than four physician visits $^{\mathrm{c}}$} & Yes & $91.4(23,444)$ \\
\hline & No & $08.6(2,197)$ \\
\hline \multirow[t]{2}{*}{ Statin dose $\mathrm{d}^{\mathrm{d}}$} & High & $33.4(8,559)$ \\
\hline & Low & $66.6(17,082)$ \\
\hline \multirow[t]{2}{*}{ Hypertension } & Yes & $56.5(14,496)$ \\
\hline & No & $43.5(11,145)$ \\
\hline
\end{tabular}

${ }^{a}$ Dispensed first statin at least one year after enrolling in the Nova Scotia Seniors' Pharmacare program; at least two dispensation dates for any medication prior to the first statin. No dispensation for cerivastatin; or any other cholesterol lowering medication; no diagnosis of renal dialysis or renal transplant in the year prior to the first statin.

${ }^{b}$ Average 2001 household income in thousands of dollars, by census enumeration area.

${ }^{c}$ During continuity assessment period.

${ }^{d}$ Low dose: atorvastatin $<20 \mathrm{mg}$, simvastatin $<40 \mathrm{mg}$, rosuvastatin $<10 \mathrm{mg}$ or any dose of pravastatin, lovastatin or fluvastatin. High dose: all other molecules and strengths.

who took less than 4 medications, those who saw a physician less than four times during the year prior to index, and those who had not been hospitalized in the year prior to the index statin had increased odds of single pharmacy use. After adjustment, urban or rural place of residence was not associated with increased odds of using a single pharmacy.
The unadjusted model indicated that subjects who frequented multiple pharmacies had slightly reduced odds of adherence compared to subjects who used a single pharmacy (odds ratio: $0.96,95 \%$ confidence interval: 0.91-1.01). After adjustment, subjects who used multiple pharmacies had 10\% decreased odds of adherence compared to subjects who used a single 
TABLE 1B Demographic and Clinical Characteristics of Subjects Who Met Inclusion Criteria ${ }^{\text {(Continu- }}$ ous Variables)

\begin{tabular}{|c|c|c|c|c|c|}
\hline$(N)=25,641$ & Mean & SD & $\begin{array}{c}\text { Mean } \\
\text { (One Pharmacy) }\end{array}$ & $\begin{array}{c}\text { Mean } \\
\text { (>1 Pharmacy) }\end{array}$ & $p$-value \\
\hline Age & 73.91 & 6.13 & 73.64 & 74.33 & $<0.001$ \\
\hline Income $^{b}$ & $46,525.33$ & $15,991.48$ & $46,304.54$ & $46,873.17$ & 0.006 \\
\hline Pharmacies used $^{c}$ & 1.57 & 0.88 & 1.00 & 2.46 & $<0.001$ \\
\hline Pharmacy visits ${ }^{c}$ & 30.40 & 22.53 & 28.52 & 33.32 & $<0.001$ \\
\hline Dispensations $^{c}$ & 51.6 & 47.8 & 48.05 & 57.20 & $<0.001$ \\
\hline
\end{tabular}

${ }^{a}$ Dispensed first statin at least one year after enrolling in the Nova Scotia Seniors' Pharmacare program; at least two dispensation dates for any medication prior to the first statin. No dispensation for cerivastan or any other cholesterol lowering medication; no diagnosis of renal dialysis or renal transplant in the year prior to the first statin.

${ }^{b}$ Average 2001 household income in thousands of dollars, by census enumeration area.

${ }^{c}$ During continuity assessment period.

TABLE 2 Unadjusted and Adjusted Odds Ratios of the Relationship Between Single Pharmacy Use and Sociodemographic and Clinical Variables in Nova Scotia Seniors' Pharmacare Beneficiaries Meeting Inclusion Criteria

\begin{tabular}{|c|c|c|c|c|c|}
\hline \multicolumn{2}{|l|}{$n=25,641$} & \multicolumn{2}{|c|}{ Unadjusted } & \multicolumn{2}{|c|}{ Adjusted } \\
\hline & & \multirow{2}{*}{\begin{tabular}{|l|} 
OR \\
1.00 \\
\end{tabular}} & \multirow[t]{2}{*}{$95 \% \mathrm{CI}$} & \multirow{2}{*}{\begin{tabular}{|l|} 
OR \\
1.00 \\
\end{tabular}} & \multirow[t]{2}{*}{ 95\% CI } \\
\hline Sex & Male & & & & \\
\hline & Female & 0.88 & $0.83-0.92$ & 0.89 & $0.84-0.94$ \\
\hline \multirow[t]{4}{*}{ Age (years) } & $\geq 80$ & 1.00 & & 1.00 & \\
\hline & $75-79$ & 1.17 & $1.09-1.27$ & 1.11 & $1.02-1.20$ \\
\hline & $70-74$ & 1.17 & $1.09-1.26$ & 1.05 & $0.97-1.13$ \\
\hline & $65-69$ & 1.38 & $1.28-1.48$ & 1.18 & $1.10-1.28$ \\
\hline \multirow[t]{4}{*}{ Income tertile ${ }^{b}$} & High & 1.00 & & 1.00 & \\
\hline & Mod & 1.13 & $1.06-1.21$ & 1.13 & $1.06-1.21$ \\
\hline & Low & 1.10 & $1.03-1.17$ & 1.11 & $1.04-1.19$ \\
\hline & Unknown & 0.77 & $0.67-0.88$ & 0.78 & $0.67-0.89$ \\
\hline \multirow[t]{3}{*}{ Place of residence } & Urban & 1.00 & & 1.00 & \\
\hline & Rural & 0.95 & $0.90-1.00$ & 1.02 & $0.97-1.08$ \\
\hline & Unknown & 0.77 & $0.14-4.18$ & 1.75 & $0.31-9.62$ \\
\hline \multirow[t]{2}{*}{ Use of greater than four medications $s^{c}$} & Yes & 1.00 & & 1.00 & \\
\hline & No & 1.80 & $1.69-.92$ & 1.56 & $1.45-1.67$ \\
\hline \multirow[t]{2}{*}{ Hospitalized $^{c}$} & Yes & 1.00 & & 1.00 & \\
\hline & No & 1.46 & $1.39-1.54$ & 1.30 & $1.23-1.37$ \\
\hline \multirow[t]{2}{*}{ Greater than four physician visits ${ }^{c}$} & Yes & 1.00 & & 1.00 & \\
\hline & No & 1.82 & $1.65-2.00$ & 1.36 & $1.22-1.50$ \\
\hline \multirow[t]{2}{*}{ Hypertension } & Yes & 1.00 & & 1.00 & \\
\hline & No & 0.97 & $0.92-1.02$ & 0.96 & $0.91-1.01$ \\
\hline
\end{tabular}

${ }^{a}$ Dispensed first statin at least one year after enrolling in the Nova Scotia Seniors' Pharmacare program; at least 2 dispensation dates for any medication prior to the first statin. No dispensation for cerivastatin; or any other cholesterol lowering medication; no diagnosis of renal dialysis or renal transplant in the year prior to the first statin.

${ }^{b}$ Average 2001 household income, by census enumeration area.

${ }^{c}$ During the continuity assessment period. 
TABLE 3 Adjusted Relationship between Single Pharmacy Use and Statin Adherence among Subjects Who Met Inclusion Criteria ${ }^{\mathrm{a}}$

\begin{tabular}{|c|c|c|c|c|c|}
\hline & \multicolumn{2}{|c|}{ Unadjusted } & \multicolumn{2}{|c|}{ Adjusted } \\
\hline & & OR & 95\% CI & OR & 95\% CI \\
\hline \multirow[t]{2}{*}{$\mathrm{UPC}^{\mathrm{b}}$} & 1.0 & 1.0 & 1.00 & 1.00 & \\
\hline & $<1.0$ & 0.96 & $0.91-1.01$ & 0.90 & $0.85-0.95$ \\
\hline \multirow[t]{2}{*}{ Sex } & Male & 1.0 & & 1.00 & \\
\hline & Female & 0.91 & $0.86-0.95$ & 0.94 & $0.89-0.99$ \\
\hline \multirow[t]{4}{*}{ Age (years) } & $\geq 80$ & 1.0 & & 1.00 & \\
\hline & $75-79$ & 1.10 & $1.02-1.19$ & 1.13 & $1.05-1.23$ \\
\hline & 70-74 & 1.10 & $1.02-1.18$ & 1.18 & $1.09-1.27$ \\
\hline & $65-69$ & 1.01 & $0.94-1.09$ & 1.13 & $1.04-1.22$ \\
\hline \multirow[t]{4}{*}{ Income tertile $e^{c}$} & High & 1.0 & & 1.00 & \\
\hline & Mod & 0.90 & $0.84-0.96$ & 0.91 & $0.85-0.97$ \\
\hline & Low & 0.85 & $0.80-0.91$ & 0.85 & $0.80-0.91$ \\
\hline & Unknown & 1.00 & $0.86-1.15$ & 0.98 & $0.85-1.14$ \\
\hline \multirow[t]{2}{*}{ Place of residence } & Urban & 1.0 & & 1.00 & \\
\hline & Rural & 0.94 & $0.89-1.00$ & 0.96 & $0.90-1.02$ \\
\hline \multirow{2}{*}{$\begin{array}{l}\text { Use of greater than four } \\
\text { medications }^{\mathrm{d}}\end{array}$} & Yes & 1.0 & & 1.00 & \\
\hline & No & 0.82 & $0.77-0.87$ & 0.97 & $0.90-1.04$ \\
\hline \multirow[t]{2}{*}{ Hospitalized $^{\mathrm{d}}$} & Yes & 1.0 & & 1.00 & \\
\hline & No & 0.76 & $0.75-0.81$ & 0.96 & $0.90-1.01$ \\
\hline \multirow{2}{*}{$\begin{array}{l}\text { Greater than four physician } \\
\text { visits }^{\mathrm{d}}\end{array}$} & Yes & 1.0 & & 1.00 & \\
\hline & No & 0.81 & $0.74-0.88$ & 0.97 & $0.88-1.07$ \\
\hline \multirow[t]{2}{*}{ Statin dose $\mathrm{e}^{\mathrm{e}}$} & High & 1.0 & & 1.00 & \\
\hline & Low & 0.953 & $0.93-1.01$ & 1.02 & $0.97-1.08$ \\
\hline \multirow[t]{2}{*}{ Hypertension } & Yes & 1.0 & & 1.00 & \\
\hline & No & 0.83 & $0.79-0.87$ & 0.85 & $0.80-0.89$ \\
\hline \multirow[t]{2}{*}{ Number of prescribers ${ }^{f}$} & 1 & 1.0 & & 1.00 & \\
\hline & $>1$ & 2.50 & $2.35-2.67$ & 2.46 & $2.30-2.62$ \\
\hline
\end{tabular}

${ }^{a}$ Dispensed first statin at least one year after enrolling in the Nova Scotia Seniors' Pharmacare program; at least two dispensation dates for any medication prior to the first statin. No dispensation for cerivastatin; or any other cholesterol lowering medication; no diagnosis of renal dialysis or renal transplant in the year prior to the first statin. ${ }^{b}$ Usual provider of care index.

${ }^{c}$ Average 2001 household income, by census enumeration area.

${ }^{d}$ During the continuity assessment period.

${ }^{e}$ Low dose: atorvastatin $<20 \mathrm{mg}$, simvastatin $<40 \mathrm{mg}$, rosuvastatin $<10 \mathrm{mg}$ or any dose of pravastatin, lovastatin, or fluvastatin. High dose: all other molecules and strengths.

${ }^{f}$ During the adherence assessment period.

pharmacy (odds ratio $0.90,95 \%$ confidence interval: 0.86-0.96). The results of the adjusted relationship are found in Table 3 . Women, subjects using 4 or less medications, subjects without hypertension and subjects with lower income had decreased odds of adherence. Subjects younger than age 80 years and subjects with more than one statin prescriber had increased odds of adherence compared to subjects with only one statin prescriber. Place of residence (urban/rural) had no apparent impact on adherence.

Altering the levels of MPR to 0.75 and 0.90 and restricting the study population to subjects residing in urban areas at the time of the index statin dispensation, to subjects who had been admitted to hospital during 
the year prior to their index statin dispensation or to those who received 13 or fewer statin dispensations did not change the direction of the result (see Table 3).

\section{DISCUSSION}

This study showed that NSSPP beneficiaries who frequented multiple pharmacies have a $10 \%$ decreased odds of adherence compared to subjects who frequented a single pharmacy for their medications (odds ratio: $0.90,95 \%$ confidence interval: 0.86-0.96). This finding has never been reported among users of a long-term cardiovascular medication. However, after a literature search, one abstract was found that showed that among adult patients with schizophrenia, those who used a single pharmacy for all of their dispensations had a $30 \%$ increased odds of adherence to antipsychotic medications compared to subjects using more than one pharmacy. ${ }^{9}$

The level of adherence and single pharmacy use obtained in this study were similar to those reported in prior research. In this study, $58.9 \%$ of subjects had a MPR of 0.80 or above and were classified as adherent to their statin over the one-year follow-up period. This is similar to previous studies assessing statin adherence, which reported adherence rates close to $50 \%$ after one year. ${ }^{29,42,43}$ In this study $60.9 \%$ of subjects attended a single pharmacy during the pre-statin period. This is similar to the $57.8 \%$ who used a single pharmacy in a previous study of adult patients with schizophrenia. ${ }^{13}$ However, our result is much lower than that of a study in the Netherlands, where $89 \%$ of subjects used a single pharmacy for all of their prescriptions, and lower than a recent CIHI report which found that $69 \%$ of seniors in Canada used only one pharmacy during a one year period. ${ }^{8,12}$ Three previous studies have detailed patient characteristics associated with exclusive pharmacy attendance. Similar to previous work, we found that increasing age is associated with increased single pharmacy use and that female sex and the use of greater than 4 medications is associated with the use of multiple pharmacies. ${ }^{8,13}$ We observed that hospitalization was associated with multiple pharmacy use. It is not known if this behaviour occurred prior to hospitalization because patients were sicker, or if it occurred after hospitalization when they may have been prescribed new medications.
We hypothesized that single pharmacy use promoted adherence because it resulted in a complete record of all medications at a single pharmacy which allowed the pharmacist to identify non-adherence. Also, single pharmacy use may have promoted a strong pharmacy-patient relationship, which allowed the pharmacist to better work with patients to improve adherence. ${ }^{7}$ However, it is possible that patients more likely to be adherent were also more likely to use a single pharmacy. Although this study indicated that single pharmacy use was associated with increased medication adherence, the association will need to be shown in different study populations, for different classes of medication and over longer time periods. If the association persists, we have provided a good description of which subjects are more likely to use a single pharmacy. If the findings are consistent, among these populations, patient behaviour and system design needs to be arranged so that the use of a single pharmacy is encouraged.

\section{Limitations}

There are some limitations of this study that may that may impact the validity of the results. The use of an administrative database limited us to the data that is contained on the NSSPP standard collection form. This introduced potential confounding due to lack of optimal information. We attempted to minimize this confounding by clustering patients at their most used pharmacy and by controlling for confounders that have been detailed in previous studies. However, we were unable to adjust the model for other confounders that could influence the relationship such as frailty, life expectancy, statin adverse effects and pharmacy effects such as prescription volume, number of pharmacy staff and pharmacist years of practice.

Enrolment into the NSSPP is not mandatory and approximately $30 \%$ of Nova Scotian seniors were not enrolled in the program at the end of the study period. ${ }^{20}$ It is likely that these persons were not missing at random: seniors not enrolled have been found to have a higher income, be taking less medications, have lower medication costs and/or to be in good health compared to program enrollees; all characteristics that may have predisposed them to higher adherence. ${ }^{30,32,46}$ Persons with fewer medications and higher income may be

J Popul Ther Clin Pharmacol Vol 24(2):e50-e60; May 30, 2017

(c) 2017 Journal of Population Therapeutics and Clinical Pharmacology. All rights reserved. 
more likely to use a single pharmacy. ${ }^{13}$ Therefore, the result may only strictly be generalized to seniors with medication coverage.

In this study we assessed the relationship between adherence to a single class of medications and the number of pharmacies used, however it is likely that participants are taking medications in addition to their statin. It is unclear if the found relationship between adherence and single pharmacy use is consistent among participants taking multiple medications. Subjects with a higher cardiovascular risk will be taking many medications in addition to their statin. Without a measure of cardiovascular risk in this study, we do not know if participants exhibiting poor adherence fit into a higher risk group than participants with low adherence. It is possible that cardiovascular risk is an effect modifier to the relationship between single pharmacy use and adherence.

\section{CONCLUSIONS}

Among seniors newly starting statin therapy, using a single community pharmacy was modestly associated with adherence. Further research will be needed to investigate whether pharmacy-based interventions might improve adherence and clinical outcomes.

\section{ACKNOWLEDGEMENTS AND FUNDING}

This work was supported by a student Scotia Scholar award from the Nova Scotia Research Foundation and was made possible through data provided by CNODES and sharing agreements between CNODES and the province of Nova Scotia. No endorsement by the province of Nova Scotia is intended or should be inferred.

CNODES is a collaborating centre of the Drug Safety and Effectiveness Network (DSEN) and is funded by the Canadian Institutes of Health Research (CIHR, Grant \# DSE-111845). The data (or portions of the data) used in this report were made available by HDNS of Dalhousie University. Although this research is based on data obtained from the Nova Scotia Department of Health and Wellness, the observations and opinions expressed are those of the authors and do not represent those of either HDNS or the Department of Health and Wellness. Ingrid Sketris and Adrian Levy have received salary support from CNODES.

\section{REFERENCES}

1. World Health Organization. Adherence to long-term therapies: Evidence for action. Available at: http://www. who.int/chp/knowledge/publications/adherence_full_report.pdf. Updated 2003. Accessed November 13, 2012.

2. Przemslaw K, Morrison V, Fargher E, et al. Ascertaining barriers for compliance: Policies for safe, effective and cost-effective use of medicines in Europe: report on the determinants of patient non-adherence with short-term therapies and treatments for chronic diseases in Europe. Available at: http://abcproject.eu/img/ABC\%20Final. pdf. Updated 2012. Accessed January 23, 2013.

3. Nieuwlaat R, Wilczynski N, Navarro T, et al. Interventions for enhancing medication adherence. Cochrane Database Syst Rev 2014;11:CD000011.

4. Mistry N, Keepanasseril A, Wilczynski NL, et al. Technology-mediated interventions for enhancing medication adherence. J Am Med Inform Assoc 2015;22(e1):e177-93.

5. Breslau N, Reeb KG. Continuity of care in a university-based practice. J Med Educ 1975;50(10):965-69.

6. Reid R, Haggerty J, McKendry R. Defusing the confusion: Concepts and measures of continuity of healthcare. Available at: http://www.cfhi-fcass.ca/Migrated/PDF/ ResearchReports/CommissionedResearch/cr_contcare_e. pdf. Updated 2002. Accessed February 11, 2013.

7. Fisher JD, Fisher WA. Changing AIDS-risk behavior. Psychol Bull 1992;111(3):455-74.

8. Buurma H, Bouvy ML, De Smet PA, et al. Prevalence and determinants of pharmacy shopping behaviour. J Clin Pharm Ther 2008;33(1):17-23.

9. Lauzier S, Gregoire J, Moisan J. Pharmacy loyalty and compliance with antipsychotics. Pharmacoepidemiol Drug Saf 2011;20:S136.

10. Pottegard A, Hallas J. Physicians' and pharmacies' overview of patients' medication. an analysis of fidelity coefficients. Eur J Clin Pharmacol 2011;67(9):919-24.

11. Evans CD, Eurich DT, Lamb DA, et al. Retrospective observational assessment of statin adherence among subjects patronizing different types of community pharmacies in Canada. J Manag Care Pharm 2009;15(6):476-84.

12. Canadian Institute for Health Information. Adverse drug reaction-related hospitalizations among seniors, 2006 to 2011 March 2013. Available at: https://secure.cihi. ca/estore/productFamily.htm?pf $=$ PFC2128\&lang $=$ en . Accessed June 28, 2013. 
13. Lauzier S, Gregoire JP, Lesage A, Moisan J. Community pharmacy loyalty among individuals with schizophrenia. Res Social Adm Pharm 2013;9(6):806-16.

14. Pittman DG, Chen W, Bowlin SJ, Foody JM. Adherence to statins, subsequent healthcare costs, and cardiovascular hospitalizations. Am J Cardiol 2011;107(11):1662-66.

15. Degli Esposti L, Saragoni S, Batacchi P, et al. Adherence to statin treatment and health outcomes in an Italian cohort of newly treated patients: Results from an administrative database analysis. Clin Ther 2012;34(1):190-99.

16. Health Data Nova Scotia. Available at: http://www. phru.dal.ca/index.cfm. Updated 20142013. Accessed August 5, 2015.

17. Nova Scotia Pharmacare. Information for All Nova Scotians. Available at: http://novascotia.ca/dhw/pharmacare/nova-scotians.asp. Accessed August 5, 2015.

18. Nova Scotia Pharmacare Programs: The Nova Scotia Seniors' Pharmacare Program. Available at: http://novascotia.ca/DHW/pharmacare/documents/seniors_pharmacare/Seniors-Pharmacare-Information-Booklet.pdf. Updated April 2013. Accessed August 4, 2013.

19. Nova Scotia Department of Health. Medical services insurance (MSI) tables, 12 months ending March 31, 2002. Available at: https://novascotia.ca/dhw/publications/annual-statistical-reports/DOH_Annual_Stat_Report_MSI_2001_02.PDF. Updated February 2003. Accessed August 5, 2015.

20. MSI Monitoring and Statistics Department, Medavie Blue Cross. Annual statistical tables, 12 months ending March 31, 2008. Available at: https://novascotia.ca/ dhw/publications/annual-statistical-reports/DOH_Annual_Stat_Report_MSI_2007_08.pdf. Updated January 2009. Accessed August 5, 2015.

21. Acri T, Gross R. Studies of Medication Adherence. In: Strom BL, Kimmel SE, Hennessy S, eds. Pharmacoepidemiology. 5 th ed. Chichester, West Sussex, UK: Wiley-Blackwell; 2012.

22. Levy AR, O’Brien BJ, Sellors C, Grootendorst P, Willison D. Coding accuracy of administrative drug claims in the Ontario Drug Benefit database. Can J Clin Pharmacol 2003;10(2):67-71.

23. Tamblyn R, Lavoie G, Petrella L, Monette J. The use of prescription claims databases in pharmacoepidemiological research: The accuracy and comprehensiveness of the prescription claims database in Quebec. J Clin Epidemiol 1995;48(8):999-1009.

24. WHO Collaborating Center for Drug Statistics Methodology.Drug ATC/DDD index 2014. Available at: http:// www.whocc.no/atc_ddd_index/. Updated December 2013. Accessed August 5, 2015.

25. Bice TW, Boxerman SB. A quantitative measure of continuity of care. Med Care 1977;15(4):347-49.

26. Hess LM, Raebel MA, Conner DA, Malone DC. Measurement of adherence in pharmacy administrative databases: A proposal for standard definitions and preferred measures. Ann Pharmacother 2006;40(7-8):1280-88.

27. Osterberg L, Blaschke T. Adherence to medication. N Engl J Med 2005;353(5):487-97.

28. Ho PM, Bryson CL, Rumsfeld JS. Medication adherence: Its importance in cardiovascular outcomes. Circulation 2009;119(23):3028-35.

29. Lemstra M, Blackburn D, Crawley A, Fung R. Proportion and risk indicators of nonadherence to statin therapy: A meta-analysis. Can J Cardiol 2012;28(5):574-80.

30. Shermock KM. Impact of continuity of care and provider factors on medication adherence in patients with hypertension [dissertation]. Johns Hopkins University, Baltimore, MD; 2009.

31. Van Wijk BL, Klungel OH, Heerdink ER, de Boer A. Effectiveness of interventions by community pharmacists to improve patient adherence to chronic medication: A systematic review. Ann Pharmacother 2005;39(2):319-28.

32. Choudhry NK, Fischer MA, Avorn J, et al. The implications of therapeutic complexity on adherence to cardiovascular medications. Arch Intern Med 2011;171(9):814-22.

33. Schers H, Webster S, van den Hoogen H, et al. Continuity of care in general practice: A survey of patients' views. Br J Gen Pract 2002;52(479):459-62.

34. Aller MB, Vargas I, Waibel S, et al. Factors associated to experienced continuity of care between primary and outpatient secondary care in the Catalan public healthcare system. Gac Sanit 2013;27(3):207-13.

35. Nutting PA, Goodwin MA, Flocke SA, Zyzanski SJ, Stange KC. Continuity of primary care: To whom does it matter and when? Ann Fam Med 2003;1(3):149-55.

36. Pittman DG, Fenton C, Chen W, Haffner S, Pendergrass M. Relation of statin nonadherence and treatment intensification. Am J Cardiol 2012;110(10):1459-63.

37. Pedan A, Varasteh L, Schneeweiss S. Analysis of factors associated with statin adherence in a hierarchical model considering physician, pharmacy, patient, and prescription characteristics. J Manag Care Pharm 2007;13(6):487-96.

38. Shalansky SJ, Levy AR. Effect of number of medications on cardiovascular therapy adherence. Ann Pharmacother 2002;36(10):1532-39. 
39. Law MR, Wald NJ, Rudnicka AR. Quantifying effect of statins on low density lipoprotein cholesterol, ischaemic heart disease, and stroke: Systematic review and meta-analysis. BMJ 2003;326(7404):1423.

40. Singer JD. Using SAS PROC MIXED to fit multilevel models, hierarchical models, and individual growth models. J Ed Behav Statis 1998;23(4):323-55.

41. Dai J, Li Z, Rocke D. Hierarchical logistic regression modeling with SAS GLIMMIX. Proceedings of the Thirty-first Annual SAS Users Group International Conference. Cary, North Carolina: SAS Institute Inc. 2006. Available at: http://www.lexjansen.com/wuss/2006/ analytics/ANL-Dai.pdf. Accessed April 3, 2013.

42. Benner J. Noncompliance with lipid-lowering medications: Implications for cost effectiveness and policy [dissertation]. Boston, MA: Harvard School of Public Health; 2002.

43. Chan DC, Shrank WH, Cutler D, et al. Patient, physician, and payment predictors of statin adherence. Med Care 2010;48(3):196-202.

44. van Walraven C, Oake N, Jennings A, Forster AJ. The association between continuity of care and outcomes: A systematic and critical review. J Eval Clin Pract 2010;16(5):947-56.

45. Oleckno WA. Essential epidemiology: Principles and applications. Long Grove, Ill.: Waveland; 2002.

46. Elliott RA, Shinogle JA, Peele P, Bhosle M, Hughes DA. Understanding medication compliance and persistence from an economics perspective. Value Health 2008;11(4):600-610. 